\title{
On the Representative CT Image of an Otic-Disrupting Fracture
}

\section{Dear Editor:}

In the article entitled "Facial Paralysis in Longitudinal versus Oblique and Otic-Sparing versus Non Otic-Sparing Temporal Bone Fracture" published in the Vol 34 No 2 issue of the Philippine Journal of Otolaryngology Head and Neck Surgery, the authors included an image (Figure 4) that was representative of an otic-disrupting fracture. The arrow clearly shows the fracture line running through the mastoid air cell system nearly parallel to the posterior external auditory canal wall and ending just posterior to the ossicular chain.

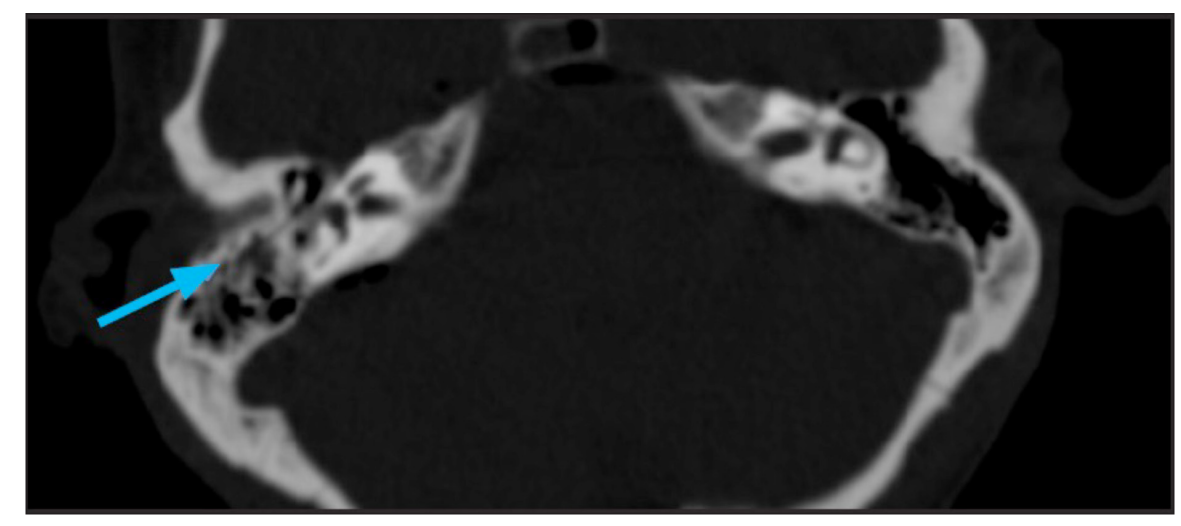

Figure 4. Representative plain temporal bone CT Scan, axial view, bone window at the level of the otic capsule showing an oticdisrupting fracture (arrow).

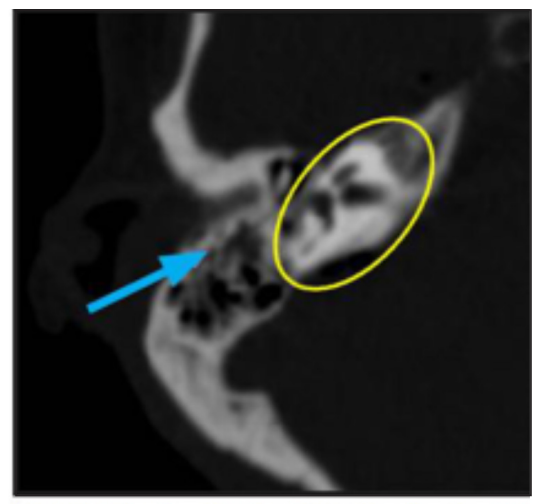

Figure 4. Representative plain temporal bone capsule showing an otic-disrupting fracture (a)

However, the fracture line does not unequivocally appear to proceed medially towards the otic capsule, which is the densest portion of the temporal bone that surrounds the osseous labyrinth, and includes the cochlea, vestibule and semicircular canals. The otic capsule likewise is located within the petrous portion of the temporal bone. ${ }^{1}$ The otic capsule lies within the oval ring in the smaller figure above which is an enlarged image of the original figure in the article.

This issue is relevant because the authors are classifying subjects according to the visual presence of a fracture that may or may not involve the otic capsule. Misidentification of the type of fracture in a representative image raises the question of a systematic misidentification in the entire data set, thus rendering the results of the study invalid.

Yours sincerely,

Nathaniel W. Yang, MD

Associate Professor and Section Head for Otology, Neurotology and Lateral Skull Base Surgery

Department of Otorhinolaryngology

College of Medicine - Philippine General Hospital

University of the Philippines Manila

Taft Avenue, Ermita, Manila 1000

Philippines

\section{REFERENCES}

1. Juliano AF, Ginat DT, Moonis G. Imaging review of the temporal bone: part I. Anatomy and inflammatory and neoplastic processes. Radiology. 2013 Oct; 269(1):17-33. doi:10.1148/ radiol.13120733. PMID: 24062560. 